\section{Erratum}

Editorial Board of the journal apologizes to our readers and authors for the error that occurred when publishing the paper by A.N. Nazarov et al. "Electrical and light emitting properties of silicon dioxide coimplanted by carbon and silicon ions" placed in the fourth issue of Vol. 11, N 4, P. 319-323, 2008. It was printed without figures that should be inserted to its text. The amended version of this paper has been placed below.

\title{
Electrical and light-emitting properties of silicon dioxide co-implanted by carbon and silicon ions
}

\author{
A.N. Nazarov, I.N. Osiyuk, S.I. Tiagulskyi, V.S. Lysenko, I.P. Tyagulskyy \\ V.N. Torbin, V.V. Omelchuk, T.M. Nazarova,* L. Rebohle**, W. Skorupa** \\ V. Lashkaryov Institute of Semiconductor Physics NAS Ukraine, 45, prospekt Nauki,03028 Kiev, Ukraine \\ *National Technical University “KPI”,37, prospekt Peremogy,03056 Kyiv, Ukraine \\ **Institute of Ion Beam Physics and Materials Research, Forschungzentrum Rossendorf e.V., POB 510119, D-01314, \\ Dresden, Germany
}

\begin{abstract}
In this paper, we explore the electrophysical and electroluminescence (EL) properties of thermally grown $350 \mathrm{~nm}$ thick $\mathrm{SiO}_{2}$ layers co-implanted with $\mathrm{Si}^{+}$and $\mathrm{C}^{+}$ ions. The implanting fluencies were chosen in such a way that the peak concentration of excess $\mathrm{Si}$ and $\mathrm{C}$ of $5-10$ at.\% were achieved. Effect of hydrogen plasma treatment on electroluminescence and durability of $\mathrm{SiO}_{2}(\mathrm{Si}, \mathrm{C})$ - Si-system is studied. Combined measurements of charge trapping and EL intensity as a function of the injected charge and current have been carried out with the aim of clarifying the mechanisms of electroluminescence. EL was demonstrated to have defect-related nature. Cross-sections of both electron traps and hole traps were determined. EL quenching at great levels of injected charge is associated with strong negative charge capture, following capture of positive charge leading to electrical breakdown of $\mathrm{SiO}_{2}$ structures.
\end{abstract}

Keywords: electroluminescence, MOS - structure, implantation, EL quenching.

Manuscript received 08.10.08; accepted for publication 20.10.08; published online 10.03.09.

\section{Introduction}

Silicon-based light emission is a promising approach to design and realize optoelectronic inter- and intrachip communication in future computer systems. Additionally, there is a great interest in multifunctional microsystems (e.g., lab-on-chip applications). Since a lot of these microsystems are based on standard $\mathrm{SiO}_{2}-\mathrm{Si}$ technology, there is also a strong demand for Si-based light emitters, especially to achieve low-cost production processes. One method for the formation of the Si-based light-emitting structures is ion beam synthesis. Electroluminescence (EL) from the Ge-rich $\mathrm{SiO}_{2}$ layers was found to be in the red/infrared and in the blue/violet spectral regions [1]. The $\mathrm{Si}$-rich $\mathrm{SiO}_{2}$ layer emits red light [2]. Ion-beam implantation using a few co-implants is of interest from two standpoints. At first, this procedure allows to expand spectral range of light emission. Secondly, co-implantation can create more stable precipitates and/or stable impurity distribution inside $\mathrm{SiO}_{2}$. Using this approach, white photoluminescence and electroluminescence of coimplanted $\mathrm{SiO}_{2}$ by silicon and carbon ions have been observed in [3] and [4], respectively. However, from our knowledge the study of electrical characteristics and degradation of electrical and luminescent properties during operation of such light-emitting devices was performed insufficiently. Thus, this paper addresses the electroluminescence, electrical characterization and their degradation in the $\mathrm{Si} / \mathrm{C}$ co-implanted $\mathrm{SiO}_{2}$ structures.

\section{Samples and experimental technique}

The $\mathrm{SiO}_{2}$ layers with $350 \mathrm{~nm}$ thickness were thermally grown on $\langle 100\rangle$-oriented n-type $\mathrm{Si}$-substrates at $1000^{\circ} \mathrm{C}$. First, the oxide films were doubly-implanted with $\mathrm{Si}^{+}$ ions at the energy of $90 \mathrm{keV}$ followed by a the second $\mathrm{Si}^{+}$implantation at $47 \mathrm{keV}$. Three sets of samples with different implanted dose were prepared. The doses were chosen in such a way that a broad implant profile with a nearly constant concentration of excess $\mathrm{Si}$ about $5 \%$, $7.5 \%$ and $10 \%$ at the depth of $60-180 \mathrm{~nm}$ below the 
oxide surface was formed. Fig. 1 shows the implantation profile calculated with the TRIM code [5]. After these implantations, the devices were furnace annealed at $1100^{\circ} \mathrm{C}$ for $30 \mathrm{~min}$ in a $\mathrm{N}_{2}$ ambient. This annealing step was carried out in order to initiate the formation of first $\mathrm{Si}$ nanoclusters that have to be acted as seeds for the final clusters. Then, $\mathrm{C}^{+}$ions at the energy $43 \mathrm{keV}$ were implanted, then followed by the second $\mathrm{C}^{+}$implantation at $22 \mathrm{keV}$. A post-implantation heat treatment at $800^{\circ} \mathrm{C}$ for $60 \mathrm{~min}$ followed by a final annealing step at $1100^{\circ} \mathrm{C}$ for $60 \mathrm{~min}$ was employed.

The investigation of the EL requires transparent and conductive gate electrodes. On the top of oxide, an indium-tin-oxide (ITO) layer, a special kind of transparent conductive oxide, was deposited using a sputtering process. The thickness of the layers was 80 $\mathrm{nm}$. The gate electrode was processed using standard lithography. The sizes of the devices were $0.5 \mathrm{~mm}$ in diameter in a periodic pattern of $2 \mathrm{~mm}$ pitch.

A portion of so fabricated MOS Light Emitting Devices (MOSLEDs) had been subjected to RF plasma treatment $(13.56 \mathrm{MHz})$ in a low pressure, diode type reactor, with the ITO electrode being exposed to the plasma discharge. The plasma working gas was a mixture of $90 \%$ nitrogen and $10 \%$ hydrogen. The plasma power density was in the range of $0.5-1.5 \mathrm{~W} \mathrm{~cm}^{-2}$. Additional substrate pre-heating from a heat source independently of the plasma discharge was used over the temperature range $100^{\circ}$ to $300^{\circ} \mathrm{C}$, and elevated temperature was maintained during the plasma treatment. The plasma treatment duration was $15 \mathrm{~min}$. Details of the plasma reactor and the used processing parameters were published in [6].

EL spectra were measured on MOSLEDs with a circular ITO at a constant current supplied by a sourcemeter Keithley 2410. The EL signal was recorded at room temperature with a monochromator Jobin Yvon Triax 320 and a photosensor module Hamamatsu H7732-10 in the range of wavelengths between 300 and $750 \mathrm{~nm}$.

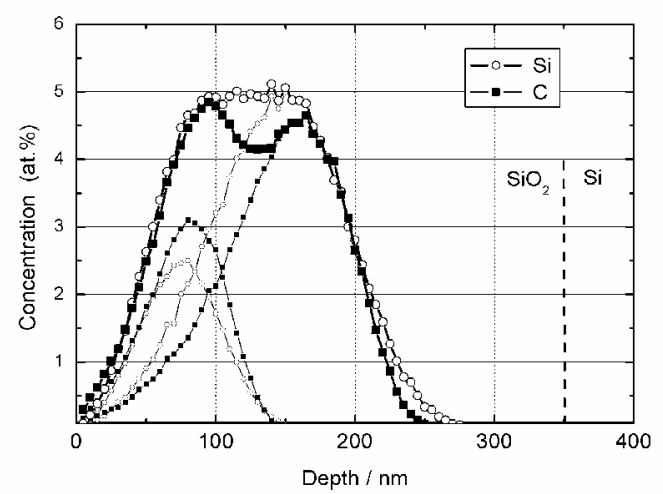

Fig. 1. TRIM-profile of a $\mathrm{Si} / \mathrm{C}$ co-implanted $\mathrm{SiO}_{2}$ layer. Two implantations at different energies were carried out for both $\mathrm{Si}$ and $\mathrm{C}$. The small symbols are related to each single implantation.
The measurement was performed with electron injection in the constant-current mode from ITO electrode into the $\mathrm{SiO}_{2}$. The typical current density for EL excitation was $10^{-3}$ down to $10^{-5} \mathrm{~A} / \mathrm{cm}^{2}$. The charge trapping during EL excitation was studied by analysing the applied voltage at constant current injection $\left(V_{\mathrm{CC}}\right)$ from the ITO to the $\mathrm{SiO}_{2}$.

\section{Results and Discussion}

\subsection{Current-voltage characteristics of $\mathrm{SiO}_{2} \mathrm{CO}-$ implanted by $\mathrm{C}^{+}$and $\mathrm{Si}^{+}$ions}

Current-voltage (I-V) characteristics for the case of electron injection from ITO into implanted $\mathrm{SiO}_{2}$ are represented in Fig. 2. The constant current regime used for the EL excitation corresponds to high-field portions in the I-V characteristics of the MOS structures. As it can be seen, cut-off injection voltage (manifested as a sharp bend in the I-V curve) shifts to lower value when dose of implantation increases; that is, EL emission arises at lower electric fields.

Actually, section of the I-V curve corresponding to the EL processes is rectified well in coordinates $\mathrm{J} / \mathrm{E}^{2}$ $1 / \mathrm{E}$, where $\mathrm{E}$ is the electric field in oxide (see Fig. 2 b). Therefore, charge transport in $\mathrm{Si} / \mathrm{C}$ implanted $\mathrm{SiO}_{2}$ is governed by Fowler-Nordheim (FN) tunneling, that is to say, by tunnel injection of carriers in the conduction band of oxide through the triangular shaped barrier. The current density of FN tunneling may be expressed, as

$$
J_{F N}=\frac{q^{3}}{8 \pi h \varphi_{B}} E^{2} \exp \left(-\frac{8 \pi \sqrt{2 m^{*} q}}{3 h E} \varphi_{B}^{3 / 2}\right),
$$

where $\varphi_{\mathrm{B}}$ is the barrier height, $\mathrm{m}^{*}$ is the effective mass of electron, other quantities are common accepted.

For the $\mathrm{Si}_{-} \mathrm{SiO}_{2}$ structures with $5 \%$ of $\mathrm{Si} / \mathrm{C}$ implants, from the slope of linear part of the $\ln \left(J / E^{2}\right)-f(1 / E)$ - dependence the barrier height has been obtained as 3,05 эB (in assumption of $\mathrm{m}^{*}=$ $\left.0.52 \mathrm{~m}_{0}\right)$.
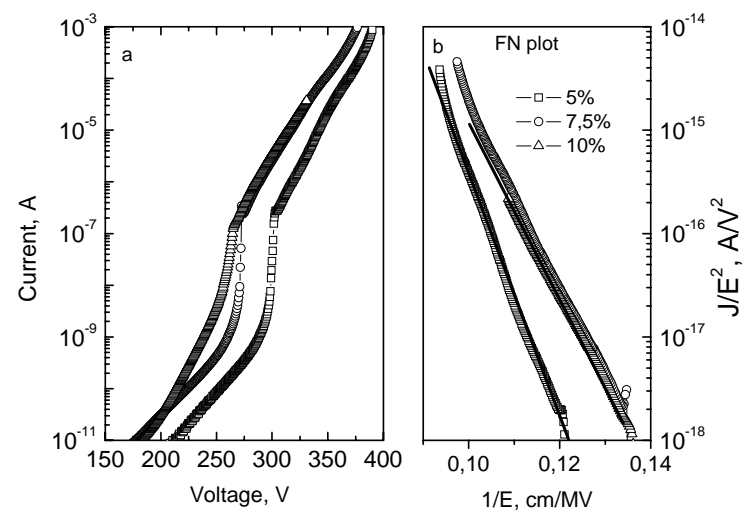

Fig. 2. The current -voltage characteristics of MOSLEDs (injection from ITO) (a); The same characteristics converted to the Fowler-Nordheim coordinates (b). 
When the dose of $\mathrm{Si} / \mathrm{C}$ implantation increases up to $10 \%$ the barrier height falls up to $2.8 \mathrm{eV}$ (at the same value of the effective mass). It is worth noting that the value is significantly lower than the injection barrier for electrons in pure $\mathrm{SiO}_{2}(3.15 \mathrm{eV}$ [7]). This phenomenon is evidence of enhancement of the electron injection into $\mathrm{SiO}_{2}$ due to the increasing concentration of SiC-related complexes and associated with trap-assisted tunneling mechanisms [8].

\subsection{Charge trapping in the $\mathrm{SiO}_{2}$ co-implanted by $\mathrm{C}^{+}$ and $\mathrm{Si}^{+}$ions}

Changes of the voltage $\left(\mathrm{V}_{\mathrm{CC}}\right)$, applied to the MOS structure, in the constant current regime of high-field electron injection from ITO as a function of injected charge are depicted in Fig. 3. The decrease of the voltage during high-field electron injection (up to $\sim 9 \cdot 10^{14} \mathrm{e} / \mathrm{cm}^{2}$ ) suggests positive charge trapping in the oxide at the distance longer that the tunneling length from the injected $\mathrm{ITO}-\mathrm{SiO}_{2}$ interface. Then, the voltage tends to steady increasing, which is indicative for negative charge trapping.

Assuming the first-order trapping kinetics the trapped charge (both negative and positive ones) versus injected charge can be described by following the expression [9]

$Q_{t}=Q_{t}^{\max }\left[1-\exp \left(-\sigma_{i} Q_{i n j}\right)\right]$

where $Q_{t}$ is the trapped charge, $Q_{t}^{\max }$ is the maximal trapped charge and $\sigma_{\mathrm{i}}$ is the effective capture crosssection of the trap.

If the trapping efficiency $(\mathrm{P})$ is presented as the first derivation with respect to the injected charge in Eq. (3.2), then we obtain

$P=\frac{d Q_{t}}{d Q_{i n j}}=\sigma_{i} Q_{t}^{\max } \exp \left(-\sigma_{i} Q_{i n j}\right)$

From Eq. (3.3), it is easy to understand that for every trap the plot of $\ln (\mathrm{P})$ vs. $\mathrm{Q}_{\text {inj }}$ will consist of linear part with the slope corresponding to $\sigma_{\mathrm{i}}$. The extrapolation to $\mathrm{Q}_{\mathrm{inj}}=0$ for this plot provides $\sigma_{\mathrm{i}} \mathrm{Q}_{\mathrm{t}}^{\mathrm{max}}$. Thus, using the proposed method [10], the number and main trap parameters can be estimated. Our calculations have demonstrated that three kind of electron traps with the average value of the capture cross-section $\left(\sigma_{\mathrm{e}}{ }^{1}=\right.$ $3.6 \times 10^{-16} \mathrm{~cm}^{2}, \sigma_{\mathrm{e}}^{2}=8 \times 10^{-18} \mathrm{~cm}^{2}$ and $\sigma_{\mathrm{e}}{ }^{3}=2 \times 10^{-19} \mathrm{~cm}^{2}$, and two kind of hole traps $\left(\sigma_{\mathrm{h}}^{1}>1 \times 10^{-14} \mathrm{~cm}^{2}\right.$, $\sigma_{\mathrm{h}}^{2}=6.6 \times 10^{-15} \mathrm{~cm}^{2}$ ) can be found by the proposed method. It should be noted that hole traps with $\sigma_{\mathrm{h}}^{2}=6.6 \times 10^{-15} \mathrm{~cm}^{2}$ are typical for $\mathrm{Si}_{-} \mathrm{SiO}_{2}$ structures with excess $\mathrm{Si}$ content in $\mathrm{SiO}_{2}$, which subjected to rapid thermal annealing [11].

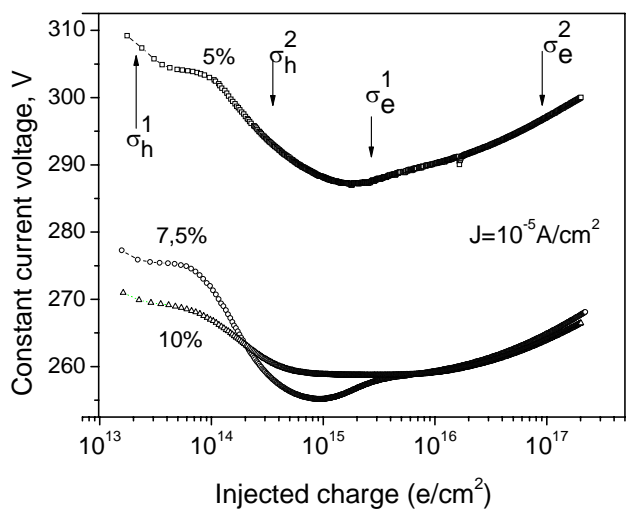

Fig. 3. Constant current voltage $\left(\mathrm{V}_{\mathrm{cc}}\right)$ as a function of the injected charge.

\subsection{The features of the EL spectra}

Fig. 4 represents EL spectra for the MOSLEDs fabricated at different implanted doses. In this experiment, the MOSLEDs were operated under electron injection from ITO at the current density $2.5 \cdot 10^{-3} \mathrm{~A} \cdot \mathrm{cm}^{-2}$. As seen from Fig. 4a, the EL spectra are relatively broad and consist of several peaks. There is visible correlation between EL spectra and the concentration of implants. The multy-Gaussian deconvolution of all the spectra was performed, and the set of band positions have been determined. For the lowest concentration (5\%), clear double-peak structure is observed with maxima close $425 \ldots 435 \mathrm{~nm}$ and $515 \ldots 525 \mathrm{~nm}$. The latter maximum belongs to a relatively broad peak that consists of two sub-peaks on its shoulders. The integral intensity of EL spectra falls down when the concentration of implanted $\mathrm{Si}$ and $\mathrm{C}$ increases, the high-energy peak decreases too, but relative intensities af broad peaks are nearly constant (Fig. 4b). Similar characteristics of photoluminescence (PL), showing a decrease of the high energy tail $(340 \ldots .410 \mathrm{~nm})$ for higher $\mathrm{Si} / \mathrm{C}$ concentration, have been observed earllier [4].

Additional measurements were carried out in order to investigate the influence of the injection current density on the shape of the EL spectrum (Fig. 5). Basically, no changes occur in the spectrum with increasing the current density and consequently also with increasing the electric field. This means that the difference in the shape of the spectra for different $\mathrm{Si} / \mathrm{C}$ concentrations is only related to the different microstructure and not to the distribution of hot electrons, but effect of the injected charge on the EL spectra demands further investigations.

Thus, we have analyzed variation of the EL spectra at high levels of injected current employing the multiscanning regime: that is EL spectra have been recorded repetitively one after another (Fig. 6). It should be noted that about $3.725 \cdot 10^{18} \mathrm{e} / \mathrm{cm}^{2}$ are injected during one EL scan. As one can see, the high energy band (within the range 390 to $400 \mathrm{~nm}$ ) is suppressed strongly when the number of EL scans is increased, during which the 
integral EL intensity decreased just linearly (see insert in Fig. 6). That is, EL quenching is observed at the used current density.
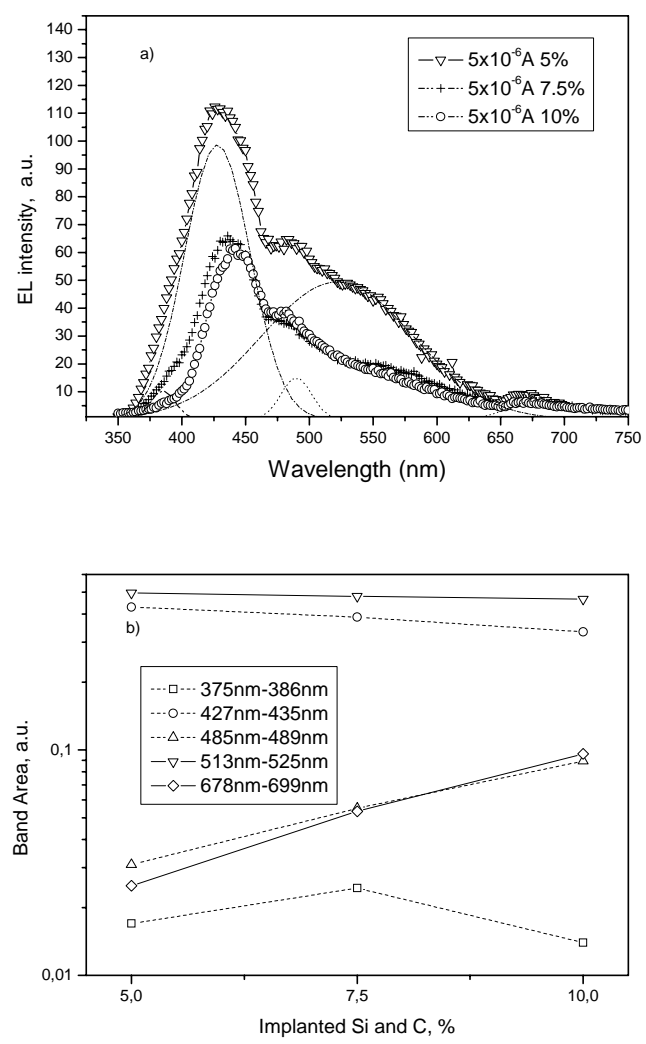

Fig. 4. EL spectra of the $\mathrm{Si}$ and $\mathrm{C}$ co-implanted $\mathrm{SiO}_{2}$ layers as a function of the implantation dose. Dashed line presents multy-Gaussian fitting for $5 \% \mathrm{Si} / \mathrm{C}$ implants. (Current of $5 \cdot 10^{-6}$ A was used for all the samples) (a); Variation of the EL intensity sub-peaks (see Fig. 4a) as a function of the implanted dose (b).

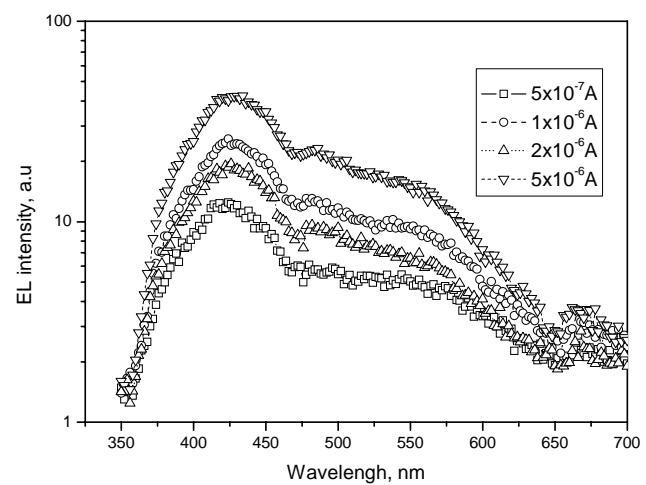

Fig. 5. EL spectra of $\mathrm{Si} / \mathrm{C}$ co-implanted MOSLEDs operating at different currents (dot area: $0.2 \mathrm{~mm}^{2}$ ).

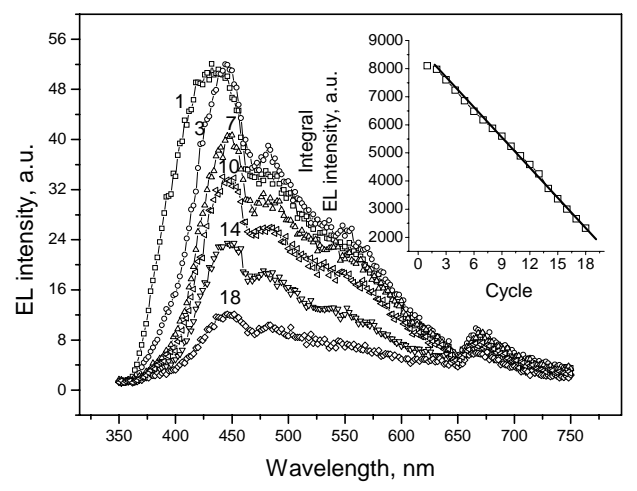

Fig. 6. EL spectra of $7.5 \% \mathrm{Si} / \mathrm{C}$ co-implanted MOSLED obtained in multi-scanned procedure at the current density $5 \cdot 10^{-3} \mathrm{~A} / \mathrm{cm}^{2}$. Scan numbers are shown near curves. Insert: variation of the integral EL intensity as a function of scan numbers.

The mechanism of the MOSLED operation is believed to be based upon impact ionization of specific defect-type luminescent centers (LCs) by hot electrons moving in the conduction band of oxide [1]. It follows from the literature that the observed line of $520 \mathrm{~nm}$ is attributed to $E_{\delta}$ center [12], lines of $385 \mathrm{~nm}$ and $490 \mathrm{~nm}$ are related to the $\mathrm{Si}-\mathrm{C}$ bonds [13] and the $\mathrm{Si} / \mathrm{C} / \mathrm{O}$ complexes [14] correspondingly, and the line at 390-400 $\mathrm{nm}$ - to the oxygen deficiency centre $(\equiv \mathrm{Si}-\mathrm{Si} \equiv)$ [15] or two-fold coordinated silicon $(=\mathrm{Si})[16]$. The line of $440 \ldots 450 \mathrm{~nm}$ can be ascribed both to $\mathrm{SiC}$ pricipitats [17, 18 ] and neutral oxygen vacancy [12]. On the low energy shoulder, one can see increase of the line $620 \mathrm{~nm}$ for the largest current density. This line is attributed to the nonbridging oxygen hole center [19].

\subsection{Effect of RF plasma treatment on light-emitting characteristics}

As it was considered earlier in [20-22], the radiofrequency (RF) plasma treatment (PT) of ion-implanted MOS structures may result in considerable modification of their structural and electrical properties. Especially, it is regarded to post implanted defects both in $\mathrm{Si}$ and $\mathrm{SiO}_{2}$. Low temperature defect annealing in $\mathrm{SiO}_{2}$ under PT can be explained within the framework of the recombination enhanced defect reactions [23, 24] caused by alternate injection both electrons and holes and there recombination at the defects.

Analysis of the hydrogen plasma effect on the $\mathrm{SiO}_{2}$ MOS structures co-implanted by $\mathrm{C}^{+}$and $\mathrm{Si}^{+}$ions allows us to reveal the following peculiarities in light-emitting and electrical properties.

1. There is an optimal regime of the hydrogen plasma treatment $\left(\sim 0.7 \mathrm{~W} / \mathrm{cm}^{2}\right)$ that results in improvement of the lifetime inherent to the device without changing its EL intensity and spectrum (see Fig. 7); 
2. Exceeding the optimal power density resulted in reduction of the integral EL intensity and transformation of the EL spectrum, namely, the high energy shoulder is considerably suppressed;

3. The increase in the power density resulted in an increase of device operation durability (Fig. 8).

The observed phenomena can be explained taking into account an effective annealing and hydrogen passivation of point defects and defect complexes in $\mathrm{SiO}_{2}$ during hydrogen plasma treatment [6]. The complicated EL spectrum of $\mathrm{SiO}_{2}(\mathrm{Si}, \mathrm{C})$-Si-structures in a wide range of a wavelength is associated with both nanoinclusions (such as $\mathrm{Si}_{\mathrm{X}} \mathrm{C}_{\mathrm{Y}} \mathrm{O}_{\mathrm{Z}}$ [14] ) and different kinds of defects, as mentioned above. Probably, availability of high concentrations for different types of defects in the $\mathrm{SiO}_{2}$ matrix shifts the reactions ordering of amorphous network towards the higher power densities used in the hydrogen plasma treatment, and ordering the $\mathrm{SiO}_{2}$ network occurs simultaneously with annealing of the defects determining the EL spectrum in our devices.

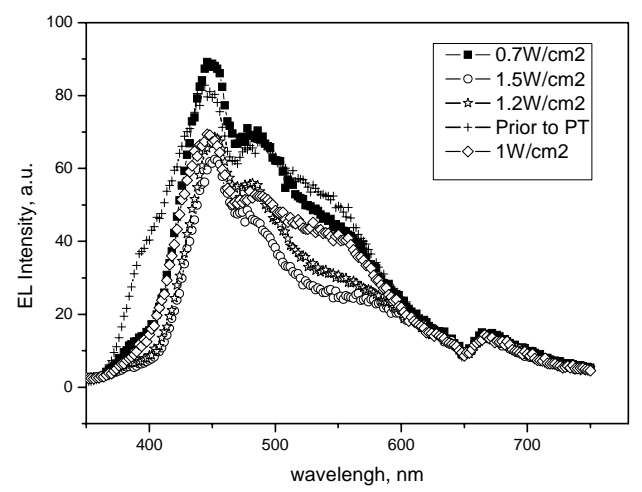

Fig. 7. Influence of plasma treatment on the EL spectra of $\mathrm{Si} / \mathrm{C}$ co-omplanted MOSLED.

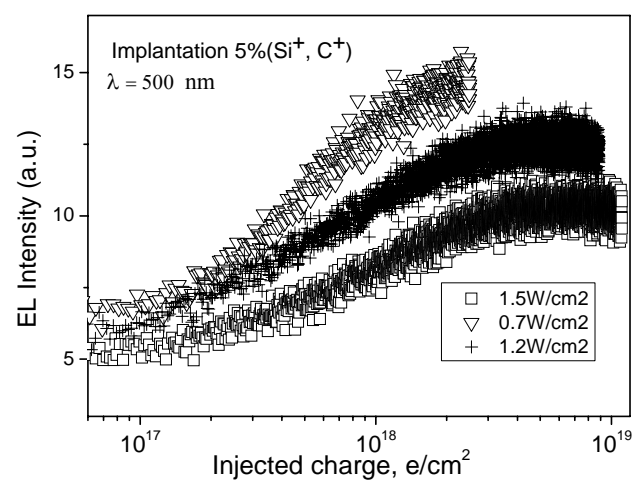

Fig. 8. EL intensity at the wavelength $500 \mathrm{~nm}$ as a function of electron-injected charge after hydrogen plasma treatment of the $\mathrm{Si}^{+}$and $\mathrm{C}^{+}$co-implanted $\mathrm{SiO}_{2}$.
3.5 Interrelation between EL and charge trapping in the $\mathrm{SiO}_{2}(\mathrm{Si}, \mathrm{C})$ - Si-structure

In order to study the relationship between the EL intensity and charge trapping in the dielectric, combined measurements of the EL intensity at the settled wavelength and the $\Delta \mathrm{V}_{\mathrm{CC}}$ versus the injected charge $\left(Q_{\text {inj }}\right)$ at high constant current levels were studied. The injected charge is simply calculated from the measurement time using the expression:

$Q_{i n j}=\int_{0}^{t} J(t) d t$

Fig. 9 demonstrates direct correlation between the EL intensity and value of the constant current voltage up to the injected charge $\sim 2 \cdot 10^{18} \mathrm{e} / \mathrm{cm}^{2}$, that is, excitation of $\mathrm{EL}$ is governed by impact ionization. When the injected charge reaches $3 \cdot 10^{19} \mathrm{e} / \mathrm{cm}^{2}$, the EL intensity tends to decrease, though the applied voltage increases. The dependence $V_{c c}$ as a function of $Q_{\text {inj manifests }}$ strong electron capture by the traps with the cross section as estimated above: $\sigma_{\mathrm{e}}{ }^{3}=2 \times 10^{-19} \mathrm{~cm}^{2}$. This process is clear seen on the $\mathrm{V}_{\mathrm{cc}}-\mathrm{Q}_{\text {inj }}$ curve for $7.5 \%$ $\mathrm{Si} / \mathrm{C}$ co-implantation (see Fig. 9).
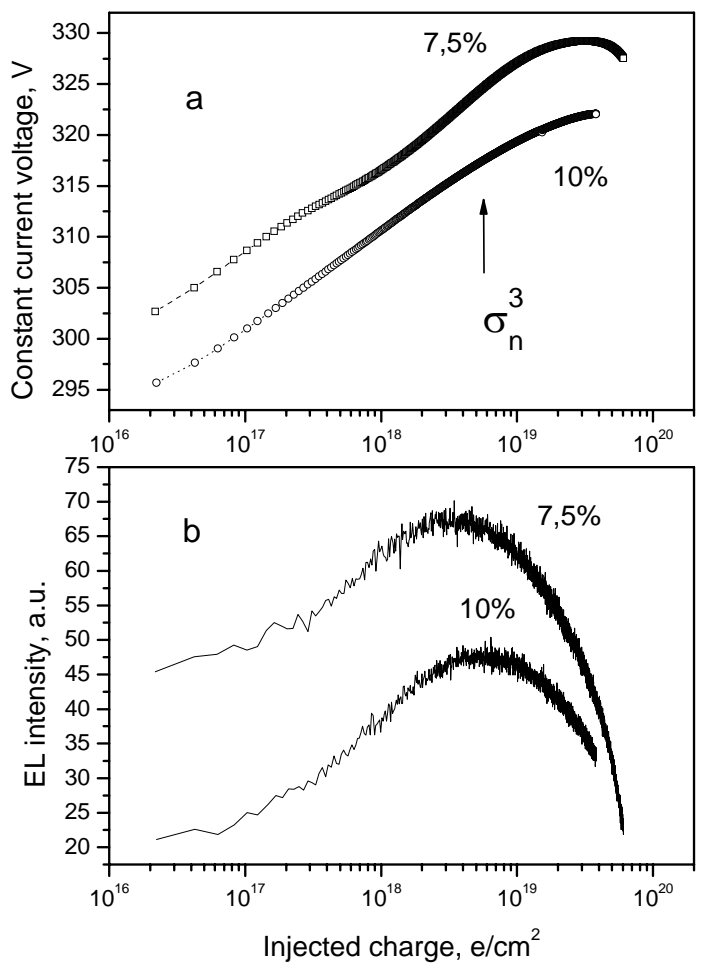

Fig. 9. Constant current voltage $\left(\mathrm{V}_{\mathrm{cc}}\right)$ as a function of the injected charge ( a); the EL intensity ( $\lambda=440 \mathrm{~nm}$ ) as a function of the injected charge (b). Injection is performed from ITO, the current density is $1 \times 10^{-3} \mathrm{~A} / \mathrm{cm}^{2}$. 
It was shown in the paper [25], that small capture cross-sections of the negative charge correlating with quenching some EL lines, are associated with a probability of defect luminescent centers reconstruction during their excitation by electron impact ionization and have to be designated for clarity as the quenching crosssection, $\sigma_{\mathrm{q}}$, for given EL line. So the value of $\sigma_{\mathrm{e}}{ }^{3} \equiv$ $\sigma_{\mathrm{q}}, 440 \mathrm{~nm}$ has to be linked with a probability of reconstruction and/or destroying the EL center, revealing a light emission at $440 \mathrm{~nm}$, with following electron trapping in the new generated defect. Since the $\mathrm{EL}$ at $440 \mathrm{~nm}$ in $\mathrm{SiO}_{2}$ can be associated with excitation of the neutral vacancy $\left(\mathrm{O}_{3} \equiv \mathrm{Si}-\mathrm{Si} \equiv \mathrm{O}_{3}\right)$ or two-fold coordinated silicon $(=\mathrm{Si})$, the quenching process can be described by the following reactions

$$
\begin{aligned}
& \mathrm{O}_{3} \equiv \mathrm{Si}-\mathrm{Si} \equiv \mathrm{O}_{3}+\mathrm{e}(\text { hot }) \rightarrow \\
& \rightarrow \mathrm{O}_{3} \equiv \mathrm{Si}^{(-)} \bullet \cdot \mathrm{Si} \mathrm{O}_{4} \\
& \mathrm{O}-\ddot{\mathrm{Si}}-\mathrm{O}+\mathrm{O}_{3} \equiv \mathrm{Si}-\mathrm{O}-\mathrm{Si} \equiv \mathrm{O}_{3}+ \\
& +2 \mathrm{e}(\text { hot }) \rightarrow \mathrm{O}_{3} \equiv \mathrm{Si}^{(-)}+\mathrm{O}_{3} \equiv \mathrm{Si}^{(-)}
\end{aligned}
$$

The reaction (3.5) assumes a breakup of Si-Si bond by a hot electron and relaxation of $\mathrm{Si}$ atom at the distance longer than $4 \AA$ with bonding to the neighboring oxygen atom. These four-fold coordinated $\mathrm{Si}$ and the silicon dangling bond can represent the electron trap [26]. In case of the reaction (3.6) two-fold coordinated $\mathrm{Si}$ interacts with broken $\mathrm{Si}-\mathrm{O}$ bond in neighbouring $\mathrm{Si}-$ $\mathrm{O}-\mathrm{Si}$ fragment that results in formation of two silicon dangling bonds $\left(\mathrm{O}_{3} \equiv \mathrm{Si}\right)$ that can work as electron traps.

Further electron injection (more than $3 \times 10^{19} \mathrm{e} / \mathrm{cm}^{2}$ ) leads to positive charge generation and drastic EL quenching (see Fig. 9). It should be noted, that capacitance-voltage characteristics of these structures demonstrate a shift along the voltage axis towards negative values, which corresponds to positive charge accumulation in oxide near the $\mathrm{SiO}_{2} / \mathrm{Si}$ interface (not shown here). Obtained results testify to positive charge accumulation/generation in the bulk and oxide interface [26]. The observed positive charge accumulation occurs jointly with electrical breakdown of the MOSLEDs.

\section{Conclusion}

Fowler-Nordheim tunnelling offers the main mechanism of charge transport in the $\mathrm{Si} / \mathrm{C}$ co-implanted $\mathrm{Si}-\mathrm{SiO}_{2}$ structures in actual for the EL voltage range.

Combined studies of the MOSLED EL intensity and charge trapping vs. time for high field electron injection into the $\mathrm{Si} / \mathrm{C}$ implanted $\mathrm{SiO}_{2}$ have shown for the first time that EL correlates well with charge trapping governed by that three kind of electron traps with the average value of the capture cross-section $\left(\sigma_{\mathrm{e}}{ }^{1}=\right.$ $=3.6 \times 10^{-16} \mathrm{~cm}^{2}, \sigma_{\mathrm{e}}^{2}=8 \times 10^{-18} \mathrm{~cm}^{2}$ and $\sigma_{\mathrm{e}}{ }^{3}=2 \times 10^{-19} \mathrm{~cm}^{2}$, and two kinds of hole traps $\left(\sigma_{\mathrm{h}}^{1}>1 \times 10^{-14} \mathrm{~cm}^{2}\right.$, $\left.\sigma_{\mathrm{h}}^{2}=6.6 \times 10^{-15} \mathrm{~cm}^{2}\right)$. The EL quenching caused by electron impact ionization resulting to reconstruction of defect LC with following electron trap generation. The quenching cross-section for the observed process is $\sigma_{\mathrm{q}, 440 \mathrm{~nm}}=2 \times 10^{-19} \mathrm{~cm}^{2}$. Positive charge generation arises at high levels of charge injection leading to electrical breakdown.

Hydrogen plasma treatment of implanted $\mathrm{SiO}_{2}$ layers containing of the nanoinclusions results in increase of the lifetime inherent to light-emitting devices and improvement of their stability without reduction in EL intensity.

\section{References}

1. L.Rebohle, J. Von Borany, H. Fröb and W.Skorupa, Blue photo- and electroluminescence of silicon dioxide layers ion-implanted with group IV elements // Appl.Phys. B 70(1), pp.1-21 (2000).

2. D.Garrido Fernandez, M.López, C.Garsía, A.PérezRodríguez, J.R.Morante, C.Bonafos, MCarrada and A.Claverie, Influence of average size and interface passivation on the spectral emission of $\mathrm{Si}$ nanocrystals embedded in $\mathrm{SiO}_{2}$ Journ.Appl.Phys. // 91 (2), pp.798-807 (2002).

3. O. Gonzalez-Varona, A. Perez-Rodrõguez, B. Garrido, C. Bonafos, M. Lopez,J.R. Morante, J. Montserrat and R. Rodrõguez, Ion beam synthesis of semiconductor nanoparticles for $\mathrm{Si}$ based optoelectronic devices Nucl. Instr. and Meth. Phys. Res. // B161-163, pp.904-908 (2000).

4. T.Gebel, L.Rebohle, J.Sun and W.Skorupa, Electroluminescence from thin $\mathrm{SiO}_{2}$ layers after Siand C-coimplantation Physica E // 16, pp.366-369 (2003).

5. J.F. Ziegler (Ed.), www.srim.org

6. A. N. Nazarov and V. S. Lysenko, RF plasma treatment as a method of radiation and thermal hydrogenation of $\mathrm{Si}$ microelectronics structures // Mikroelektronika 23 (4), pp. 45-64 (1994) (in Russian).

7. Z. A. Weinberg and A. Harstein, Effect of silicon orientation and hydrogen annealing on tunneling from Si into $\mathrm{SiO} 2 / /$ J. Appl. Phys. 54, pp. $2517-$ 2521 (1983).

8. M.P. Houng, Y.H. Wang, W.J. Chang, Current transport mechanism in trapped oxides: A generalized trap-assisted tunnelling model // J.Appl.Phys. 86 (3), pp. 1488-1491 (1999).

9. V.V. Afanas'ev and V.K. Adamchuk, Injection spectroscopy of localized states in thin insulating layers on semiconductor surfaces // Progress in Surface Science 47, pp. 1-301 (1994).

10. T.N. Ning and H.N. Yu, Optically indused injection of hot electrons into $\mathrm{SiO}_{2} / /$ Journ.Appl. Phys. 45(12), pp.5373-5378 (1974).

11. A. Nazarov, W. Skorupa, I.N.Osiyuk, I.P. Tyagulskii, V.S. Lysenko, R.A. Yankov, T. Gebel, Comparative Study of Charge Trapping in HighDose $\mathrm{Si}$ and Ge-Implanted $\mathrm{Al} / \mathrm{SiO}_{2} / \mathrm{Si}$ Structures // Journal of The Electrochemical Society, 152 (2), pp. F20-F25 (, 2005). 
12. Gong-Ru Lin, Chung-Jung Lin, Improved bluegreen electroluminescence of metal-oxidesemiconductor diode fabricated on multirecipe $\mathrm{Si}$ implanted and annealed $\mathrm{SiO}_{2} / \mathrm{Si}$ substrate // J.Appl.Phys. 95 (12), pp. 8484-8486, (2004).

13. B. Garrido, M.López, S.Ferré, A.RomanoRodrigues, A.Pérez-Rodrigues, P.Rutewrana and J.R. Morante, Visible photoluminescence of $\mathrm{SiO}_{2}$ implanted with carbon and silicon // Nucl.Instr. and Meth. Phys. Res. B120(1), pp.101-105 (1996).

14. A.Pérez-Rodrigues, O.González-Varona, B.Garrido, P.Pelegrino, J.R. Morante, Wight luminescence from $\mathrm{Si}^{+}$and $\mathrm{C}^{+}$ion-implanted $\mathrm{SiO}_{2}$ films // J.Appl.Phys, 94(1),pp.254-262 (2003).

15. A.Anneda, C.M. Carbonaro, F. Clemente, R.Corpino, Ultraviolet excitation fine tuning of luminescent bands of oxygen deficient centers in silica // J.Appl.Phys, .92 (6), pp.3034-3038 (2002).

16. [16] L.Skuja, Optical properties of defects in silica, in Defects in $\mathrm{SiO}_{2}$ and Related Dielectrics: Science and Technology, Eds. G.Pacchioni, L.Skuja, D.L.Griscom, Ser.2, Vol 2,p.73-116, Kluwer, Dordrecht (2000).

17. O. González-Varona, C. Bonafos, M. López, B. Garrido, A. Pérez-Rodríguez, J. R. Morante, J. Montserrat and R. Rodríguez, Synthesis of luminescent particles in $\mathrm{SiO}_{2}$ films by sequential $\mathrm{Si}$ and $\mathrm{C}$ ion implantation // Microelectronics Reliability 40 (4-5), pp. 885-888 (2000).

18. O. González-Varona, B. Garrido, A. PérezRodríguez, J. R. Morante, C. Bonafos, M. Carrada, L. F. Sanz, M. A. González and J. Jiménez, Analysis of the white emission from ion beam synthesised layers by in-depth resolved scanning photoluminescence microscopy // Mater.Sci.Eng. B91-B92 (1), pp. 51-54 (2002).

19. M.Ya.Valakh, V.A.Yukhimchuk, V.Ya.Bratus', A.A.Konchits, P.L.F.Hemment, T.Komoda, Optical and electron paramagnetic resonance study of lightemitting $\mathrm{Si}^{+}$ion implanted silicon dioxide layers // J.Appl.Phys. 85(1), pp.168-173 (1999).

20. V.S.Lysenko, M.M.Lokshin, A.N. Nazarov and T.E.Rudenko, RF plasma annealing of implanted MIS structures // Phys.Stat.Sol(a) 88 (2), pp.705712 (1985).

21. V.V. Artamonov, V.S.Lysenko, A.N. Nazarov, V.V. Strelchuk, M.Ya.Valakh and I.M. Zaritskii, Relaxation of amorphous structure of implanted Si under RF plasma treatment: Raman and EPR study // Semicond. Sci. Technol .6 (2), pp.1-5 (1990).

22. A.N.Nazarov, V.I.Kilchitska, I.P.Barchuk, A.S. Tkachenko and A.Ashok, Radio frequency plasma annealing of positive charge generated by Fowler-Nordheim electron injection in buried oxides in silicon // J.Vac.Sci.Technol. 18 (3), pp.1254-1261 ( 2000).

23. L. C. Kimmerling, Recombination enhanced defect reactions // Sol. St. Electron. 21 (11-12), pp.13911401 1978).
24. T. P. Ma and M. P. Chin, RF annealing mechanisms in metal-oxide-semiconductor structures - an experimental simulation // J. Appl. Phys. 51 (10), pp. 5458-5463 (1980).

25. A.N. Nazarov, I.N. Osiyuk, J.M. Sun, R.A.Yankov, W. Skorupa, I.P. Tyagulskii, V.S. Lysenko, S. Pruchnal, T. Gebel, L. Rebohle, Quenching of electroluminescence and charge trapping in highefficiency Ge-implanted MOS light-emitting silicon diodes // Appl. Phys. B 87, pp. 129-134 (2007).

26. C. J. Nicklaw, Multi-level modeling of total ionizing doze in a-SiO2: First principles to circuits // Thesis, Vanderbilt University 2003, p. 163. 